\title{
Observational learning in Gallus gallus domesticus with and without a conspecific model
}

\author{
SUZANNE B. JOHNSON, ROBERT J. HAMM, and THOMAS H. LEAHEY \\ Virginia Commonwealth University, Richmond, Virginia
}

\begin{abstract}
Following training to eat from the grain hopper, different groups of chickens were exposed to a positive correlation between keylight and food-hopper operation or to observation of another chicken (model) keypecking in response to the presentation of the keylight and grain. During the training phase, subjects were separated from the key and grain by a transparent partition. When given access to the key and grain, chickens that had observed the model responded earlier and more frequently than subjects that had only observed the correlation between stimuli or had no observational training. In addition, subjects that had observed the correlation of keylight and grain responded sooner and more often than did the group given no observational training. These results confirm that birds can learn through observation, and that the observation of a conspecific model can enhance that learning.
\end{abstract}

In the present study, we investigated observational learning under experimental conditions designed to take advantage of the organism's natural abilities by studying observational learning of an autoshaped pecking response in chickens. Brown and Jenkins (1968) found that when birds were presented with a lighted key that preceded food delivery, they learned to peck the key with a high probability. Brown and Jenkins referred to this response acquisition as autoshaping, since the animals learned to respond automatically (i.e., without the usual experimenter involvement in shaping the response). As stated by Brown and Jenkins, "the emergence of the keypeck may be characterized as a process of autoshaping on which a direction is imposed by the species-specific tendency of the pigeon to peck at things it looks at" (p. 7). Thus we chose the autoshaped keypeck response as a reasonable experimental analog of a naturally occurring behavior among birds.

A second rationale for investigating autoshaping is that the results of two previous experiments examining whether birds can learn a pecking response by observation of the correlation between the keylight and grain have been ambiguous. In Brown's (1976) study, different groups of pigeons observed either positive, zero, or negative correlations between the keylight and inaccessible food. When the groups were tested with accessible food, the group that had previously observed the positive correlations between the keylight and food pecked sooner and more frequently than did the other groups. However, this result was not confirmed by Oberdieck, Strong, and Cheney (1979). They compared the performance of pigeons that had been exposed to a positive association of keylight and inaccessible grain to a group given no prior

The authors' mailing address is: Department of Psychology, Virginia Commonwealth University, 810 West Franklin Street, Richmond, VA 23284. observational training and found no differences in the rates at which the groups learned the pecking response on the subsequent autoshaping test.

Because the results of these studies conflicted, the present experiment included not only a condition in which birds observed the correlation between stimuli but also one in which subjects observed a conspecific model's being autoshaped. The inclusion of a model condition was an attempt to make the experimental procedure more ecologically valid. That is, if an animal species is capable of learning by observation, it should be most apparent after observation of a conspecific.

\section{METHOD}

\section{Subjects}

The subjects were 18 individually housed Black Old English Bantam hens approximately 1 year old. Birds were obtained from local breeders in the Richmond, Virginia area. Weights of the hens ranged from 190.5 to $475.4 \mathrm{~g}$ with a mean of $367.7 \mathrm{~g}$. Prior to the experiment, subjects were brought to and maintained at $80 \%$ of their free-feeding weights by restricting their daily food ration. Water and grit were freely available in their home cages throughout the experiment. The animal colony had a 16-h-light/8-h-dark cycle and a room temperature of $20^{\circ}-22^{\circ} \mathrm{C}$.

\section{Apparatus}

Three identical one-key experimental chambers (BRS/LVE Model PIP$015)$ with interior dimensions of $35 \times 31 \times 34 \mathrm{~cm}$ were used. A transparent Plexiglas wall was inserted in each chamber to create an observation area $(13.5 \times 31 \times 34 \mathrm{~cm})$ and response area $(21.5 \times 31 \times 34 \mathrm{~cm})$. The response area contained the response key and grain hopper. The $3-\mathrm{cm}$ diameter key was located $25 \mathrm{~cm}$ above the grid floor and was centered on the midline of the front wall. An Industrial Electronic Engineers one-place digital readout (Model 10-029-1820L) permitted transillumination of the response key. An effective force of $0.15 \mathrm{~N}$ was required to activate the key. The food magazine was located $9 \mathrm{~cm}$ above the grid floor and directly below the response key. The sources of illumination were the keylight, the food magazine light, and the houselight mounted over the stimulus panel. White noise was introduced into the experimental chamber to mask extraneous auditory stimuli.

A Hewlett-Packard 9825T microcomputer was interfaced with Coulbourn Instruments DynaPort (Model S18-10) and other solid-state programming modules to control stimulus events and response recording. 


\section{Procedure}

Training. Magazine training was instituted during the first session for each chicken. Subjects were placed in the response area of the chamber with houselights on and keys darkened. The grain magazine was operated five times for $5 \mathrm{sec}$ on a variable-time schedule with a mean intertrial interval of $30 \mathrm{sec}$ (VT 30-sec). All chickens quickly learned to eat from the hopper.

Observation phase. The subjects were randomly assigned to one of three groups $(N=6)$. After magazine training, each individual of the first group, the stimulus group, was placed in the observation area of the chamber to observe 10 sessions of CS(keylight)-US(grain) correlations. Each CS presentation was 6 sec long and was immediately followed by a response-independent 5-sec US presentation. Forty CS-US trials were presented during each session. The mean intertrial interval (ITI) was $30 \mathrm{sec}$.

Subjects in the second group, the model group, were magazine trained and placed in the observation area of the chamber to observe a previously trained chicken responding to the keylight-grain presentations in the response area. As in the first group, there were 10 sessions of 40 trials with a 6-sec CS presentation immediately followed by a 5-sec US presentation. The variable ITI averaged $30 \mathrm{sec}$.

Subjects in the third group, the control group, were magazine trained and were immediately moved to the next phase of the procedure without any observational training.

Autoshaping transfer test. After completing the training outlined above, all subjects were placed in the response section of the chamber and were presented with CS-US pairings. As before, the CS was a 6sec illumination of the key, and the US was a 5-sec operation of the food hopper. Forty CS-US trials with a variable ITI (mean of $30 \mathrm{sec}$ ) were presented for each of three sessions.

\section{RESULTS}

Two measures of keypecking during the autoshaping transfer test were analyzed: number of trials until the first response and number of responses to the CS. Table 1 lists the trials to first response for individual subjects and also group medians. In order to test for group differences in the trials to the first response, Mann-Whitney $U$ tests were performed. The Mann-Whitney test revealed that the stimulus group responded earlier than did the control group $[U(6,6)=5, p=.021]$, that the model group responded earlier than did the control group $[U(6,6)=$ $0.5, p=.001]$, and that the model group responded earlier than did the stimulus group $[U(6,6)=1.5, p=.01]$.

To show the different rates of response acquisition for each group, trials on the first transfer test day were divided into four blocks of 10 trials each, and the number of pecks emitted in each trial block was calculated (see Figure 1). These data were analyzed by a 3 (group) $\times 4$ (10-trial block) analysis of variance (ANOVA). This analysis yielded a significant group main effect $[F(1,15)=3.97$,

Table 1

Trials to First Response for Subjects in Each Group

\begin{tabular}{cccc}
\hline $\begin{array}{c}\text { Subject } \\
\text { Number }\end{array}$ & $\begin{array}{c}\text { Model } \\
\text { Group }\end{array}$ & $\begin{array}{c}\text { Stimulus } \\
\text { Group }\end{array}$ & $\begin{array}{c}\text { Control } \\
\text { Group }\end{array}$ \\
\hline 1 & 6 & 47 & 26 \\
2 & 2 & 15 & 24 \\
3 & 1 & 5 & 22 \\
4 & 1 & 2 & 26 \\
5 & 1 & 10 & 17 \\
6 & 1 & 9 & 75 \\
Median & 1 & 9.5 & 25 \\
\hline
\end{tabular}

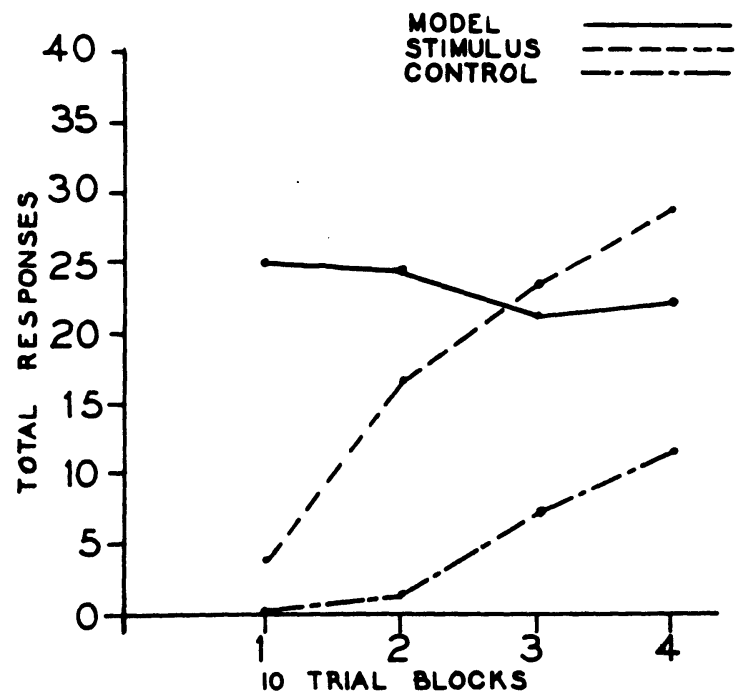

Figure 1. Mean responses of the three groups over the four 10trial blocks that comprised the first session during the autoshaping transfer test.

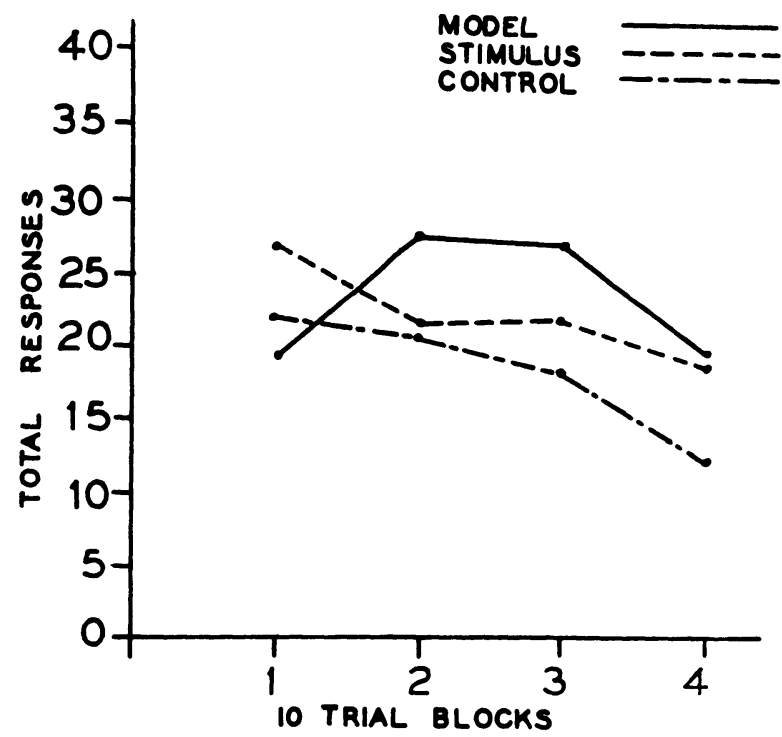

Figure 2. Mean responses of the three groups over the four 10trial blocks that comprised the second session of the autoshaping transfer test.

$p<.01]$, block effect $[F(3,45)=3.75, p<.01]$, and a group $\times$ block interaction $[F(6,45)=2.36, p<.05]$.

A series of Duncan's multiple-range tests were conducted to examine the group differences in responses over trial blocks ( $\mathrm{p}<.05$ for all contrasts). On Blocks 1 and 2 , the model group responded more frequently than did the control group, and the stimulus group responded more frequently than did the control group. On Block 3, the model group responded more frequently than did the control group and less frequently than did the stimulus group. There were no significant differences between groups on Block 4. 
Figure 2 shows the total responses for each group in four 10-trial blocks for Day 2 of the transfer test. As the figure suggests, by Day 2 all groups had learned the keypecking response and were maintaining a consistent rate of responding. This was confirmed by a 3 (group) $\times 4$ (10-trial block) ANOVA on the data, which found no significant effects. Similarly, an ANOVA for Day 3 yielded no significant effects.

\section{DISCUSSION}

The first objective of this experiment was to test whether birds can learn the keypecking response from the observation of the correlation of an inaccessible keylight and grain, a question raised by the conflicting results obtained by Browne (1976) and Oberdieck et al. (1979). The results of the present experiment confirmed Browne's conclusions by showing clearly that chickens that observed six sessions of the association of a keylight and grain magazine from behind a transparent barrier pecked sooner and more frequently on an autoshaping transfer test than did subjects having no prior observational training. A major procedural difference between this experiment and that of Oberdieck et al., whose results were not replicated, is that subjects in the present experiment observed from behind a transparent barrier separating the subjects from the manipulandum. In the Oberdieck et al. study, birds had access to the key throughout observational training. Although the importance of this procedural difference was not explicitly tested, it is interesting to note that observational experiments using rats (Del Russo, 1975; Denny, Bell, \& Clos, 1983; Kohn \& Dennis, 1972) and monkeys (Darby \& Riopelle, 1959) did not allow the subjects to have access to the manipulandum or discriminative stimuli during observational training. Having access to the key and being blocked from eating the grain produce extinction-like or latent inhibition effects. In other words, the subject learns an association between keylight and inaccessible grain, and this association inhibits response acquisition. Whatever the cause for the difference in results, the present experiment demonstrates that birds can learn by the simple observation of stimulus correlations.

The second objective of this research was to investigate the contribution of a conspecific model to observational learning. Results showed that the presence of a conspecific model performing the pecking response during the observation period enhanced the acquisition of the keypecking response during the autoshaping transfer test. In fact, 4 of the
6 subjects in the model condition responded on the first trial of the transfer task (see Table 1). Obviously, these subjects had learned the association between the keylight and grain and were prepared to respond immediately when given access to the key and grain. The most obvious difference between the model-present and model-absent conditions is that when the model was present, the observer was able to see the keypecking response being performed. Thus, in the model condition, the subjects not only observed the correlation between keylight and grain (S-S association), they also had the opportunity to observe keylightresponse (S-R) and response-grain (R-S) associations. The data of the present experiment demonstrated that the observation of these additional correlations facilitates the acquisition of the response to the keylight and grain. Thus, the results of the present experiment demonstrate that birds can learn by observation and the observation of a conspecific model can enhance that learning.

\section{REFERENCES}

Brown, P. L., \& Jenkins, H. M. (1968). Auto-shaping of pigeon's key-peck. Journal of the Experimental Analysis of Behavior, 11, 1-8. BrownE, M. P. (1976). The role of primary reinforcement and overt movements in auto-shaping in the pigeon. Animal Learning \& Behavior, 4, 287-292.

DARBY, C. L., \& Riopelle, A. J. (1959). Observational learning in the rhesus monkey. Journal of Comparative Physiological Psychology, 52, 94-98.

Del Russo, J. E. (1975). Observational learning of discriminative avoidance in hooded rats. Animal Learning \& Behavior, 3, 76-80.

Denny, M. R., Bell, R. C., \& Clos, C. (1983). Two-choice, observational learning and reversal in the rat: S-S versus S-R effects. Animal Learning \& Behavior, 11, 223-228.

KoHN, B., \& DENNIS, M. (1972). Observation and discrimination learning in the rat: Specific and nonspecific effects. Journal of Comparative Physiological Psychology, 78, 292-296.

Oberdieck, F., Strong, R., \& Cheney, C. (1979, November). The effect of observing positive CS-US correlations on subsequent autoshaping. Paper presented at the meeting of the Psychonomic Society, Phoenix, AZ.

Romanes, G. J. (1983). Animal intelligence. New York: AppletonCentury-Crofts.

(Manuscript received for publication December 4, 1985.) 